\title{
Food quality in domestic markets of developing economies: A comparative study of two countries
}

\author{
Anneleen Vandeplas ${ }^{1}$ \\ DG Economic and Financial Affairs, European Commission and \\ LICOS - Center for Institutions and Economic Performance and Faculty of Business and \\ Economics, KU Leuven, Belgium \\ Bart Minten \\ Development Strategy and Governance Division, \\ International Food Policy Research Institute, Addis Ababa Office
}

\begin{abstract}
Food quality has become an important determinant of success in global food trade and growers for international markets have to continuously adjust to buyers' requirements. It is however not clear to what extent there is a demand for food quality - and how much buyers are willing to pay for it - in domestic food markets of developing economies. Based on unique comparable price and trader data in a poor country in Africa (Madagascar) and an emerging economy in Asia (India), we compare food quality and quality's pricing. We find significantly better quality and higher quality premiums (using revealed as well as stated preference methods) in India than in Madagascar. These findings are consistent with a simple theoretical model, solely based on average income gaps between the two countries.
\end{abstract}

Keywords: Food quality, quality premiums, development JEL codes: Q12, Q13, L15

\footnotetext{
${ }^{1}$ Corresponding author: Anneleen Vandeplas, email address: anneleen.vandeplas@ec.europa.eu. This paper was written before Anneleen Vandeplas joined the European Commission, while she was a Post-doctoral fellow of the Research-Foundation Flanders (FWO). Opinions expressed in this paper are those of the authors and do not necessarily reflect the view of their institutions.
} 


\section{Introduction}

Food quality and safety have become important concerns in global food markets. This is also increasingly so in developing countries (Swinnen, 2007; Reardon et al., 2003; World Bank, 2007). While private and public regulations on quality and safety have important impacts on developing countries' agricultural production systems through export markets, it has been argued that quality and safety considerations are also becoming increasingly important for domestic markets of developing countries (World Bank, 2005). To date, however, there is limited empirical evidence on the demand for quality and safety in these markets and how much consumers are willing to pay for it.

This topic is important for various reasons. First, if demand for quality and safety is high and/or changing, investments should be oriented towards developing varieties that have specific quality characteristics or towards better and safer post-harvest technologies (see for example Unnevehr, 1986). If customers attach little value to quality or safety, there will be few rewards for the adoption of costlier high-quality products or better postharvest processing or preservation methods. In such an environment, it seems the highest pay-off for food technology development would then be in productivity-increasing or input-costs reducing varieties.

Second, growing demand and willingness-to-pay for quality may lead to market transformation. For instance, changing preferences may be important determinants of market opportunities for modern retail chains, which are often focused on products in the higher quality ranges (Reardon et al., 2003). In many countries, it has been observed that the take-off of investments by modern retail chains sparks a much broader sector-wide structural transformation of local agricultural supply chains with important implications for small farmers (e.g. Reardon and Timmer, 2007). In addition, if local supply chains fail to deliver the quality consumers ask for, consumers may turn to imported products, and important opportunities for local value creation may be missed.

Third, the literature shows that consumers change from low-quality to high-quality commodities with increasing incomes (e.g. Deaton and Muellbauer, 1980; Pingali, 2004). 
Several empirical studies illustrate that in the process of development, consumers shift from less expensive staple foods such as cereals to more expensive 'high-value' foods such as fruits and vegetables, meat and dairy (e.g. Ye and Taylor, 1995; Sahn, 1988; Joshi et al., 2007; Ito et al. 1989). However, there is much less literature exploring the impact of income on the demand for different qualities of a particular food item. Ignoring these quality issues within food items in empirical food demand analysis and projections might lead to substantial bias (Deaton, 1988; Yu and Abler, 2009).

In this paper, we make three contributions to the international literature in this area. First, we have collected unique primary data on food quality indicators for two identical commodities in the domestic markets of India and Madagascar, two countries that are poor but at different stages of development, and we empirically explore the differences in quality and quality's pricing between these countries. We find that the food quality ${ }^{2}$ on offer and the quality premium differ markedly between these settings. Second, we develop a theoretical model which can potentially explain the differences in food quality solely based on the significant average income differences that exist between these two countries. Our simple model predicts that as incomes rise, food market transformation will be driven by two factors, notably a growing demand for quality and an increasing price premium for quality. Third, we implement and compare the results of stated and revealed preference methods to assess the value of food quality and of food attributes. These methods have rarely been implemented in tandem in a developing country setting.

\section{Data collection}

A primary survey on food quality and its pricing was organized with traders in traditional market outlets in similar sized cities in a poor country in Africa (Madagascar) and an emerging country in Asia (India).

\footnotetext{
${ }^{2}$ We focus on the demand for search attributes and more in particular on value attributes - reflecting organoleptic aspects of quality (in particular appearance and aroma). According to Bowbrick (1982), these are surrogates for flavor. The advantage of such attributes is that they are directly observable and that information asymmetries, which are important in the case of credence and experience goods, can be ignored.
} 
First, we conducted a survey in Antananarivo, the capital of Madagascar. Here, traditional food retailing is done through different outlets. The most important one is the traditional daily market, where food is sold by several traders in a designated area. Traders specialize in specific products and often sell only those. Traders of similar products are usually clustered in the same area within the market. Second, micro-retailers or street-sellers also specialize in specific products, sell in micro-quantities, and operate often without formal registration, outside formal markets, and outside regular hours. Third, small shops (épiceries) might sell different types of food on top of a variety of other basic products.

Second, a survey was conducted in Dehradun, the capital of Uttarakhand, a state in the North of India. Here, fruits and vegetables are usually marketed by hawkers. Hawkers can have a permanent shop along the street, but usually rely on push carts, which they use to transport their merchandise from (mostly public) wholesale markets to a strategically well-chosen location close to consumers' homes. The push carts allow for mobility and many hawkers crisscross the city in the morning, delivering fresh fruits and vegetables to people's homes on a daily basis. In the afternoon, they typically sell at smaller wet markets where consumers can visit them. In these settings, customers seem to prefer buying fruits and vegetables daily in relatively small amounts, partly because many households did not own a refrigerator yet at the time of our survey.

Staples like rice, being easier to store, are often bought in larger amounts and not on a daily basis. In one particular neighborhood of Dehradun, close to the public cereals wholesale market, there are many specialized rice and cereal shops, with favorable prices, where households buy their rice in bulk. Alternatively, consumers may shop at "momand-pop" stores (kirana stores), where loose rice is sold in whichever quantity required. Under some conditions, poor households have access to ration cards that allow them to buy rice at below market rates through the Public Distribution System, a safety net subsidized by central as well as state governments. 
Our research focuses on two major products: on the one hand rice, the main staple in both countries, which represents around $50 \%$ and $40 \%$ of the calories consumed by an average Malagasy and Indian citizen respectively; on the other hand tomato, a major vegetable commonly used in local dishes in both countries. The implemented survey questionnaires included information on basic socio-economic characteristics of traders, purchase and sales practices, perceived price differences of specific quality attributes, and actual prices charged for the types of products traders sell, together with a detailed description based on a list of quality indicators.

The Madagascar survey was conducted during November/December 2006 in several districts of Antananarivo. Almost 450 traders were interviewed in total, of which 233 rice traders and 205 tomato traders. The sampling was set up as follows. Six districts within the city were selected. In these districts, a census was carried out of all the shops, streetsellers and sellers on traditional retail markets that sold these two products. About 30 traditional retailers, 5 streetsellers and 5 shops (if they existed) were randomly selected in each district. In addition to the retailers, all wholesalers in rice and tomatoes in Antananarivo were visited and interviewed. ${ }^{3}$ No street sellers of rice could be found in the areas that were surveyed. In the case of tomato traders, no shops (épiceries) could be identified that would carry those.

For the India survey, around 300 traders were interviewed in Dehradun, notably 151 rice traders and 157 tomato traders, in December 2007. More specifically, 70 rice traders were interviewed at Hanuman Chowk, the area where most of the rice wholesalers are located. Many of these wholesalers are also retailers. The remainder of the rice traders were selected through geographical stratification. Dehradun counts 60 "wards" (subdivisions of the city), each with a population of approximately 10,000. We randomly selected 2 wards in respectively the east, the west, the north and the south of Dehradun - in total 8 wards. In each of these wards, a census was done of all the retailers, and based on data from this census, 10 rice retailers were randomly chosen. This yielded another 80 rice traders. As for the tomato traders, we interviewed 70 traders on the four major retail

\footnotetext{
${ }^{3}$ A dozen wholesalers refused to be interviewed.
} 
markets of the city (Old Subzi mandi, Tehsil market, Dharampur market and the Niranjanpur mandi); 80 other retailers were selected through geographical stratification in the same wards where the rice traders were selected.

\section{Descriptive statistics}

Table 1 gives a description of respondents in the sample. A few striking differences between traders of different commodities stand out. Only one-third of the tomato traders are male in Madagascar. This number is significantly higher for rice. A specialization in products by gender has also been observed in other countries (e.g. Harriss-White, 1999). Tomato retailers have less experience in trade than rice retailers. Education levels of retailers are relatively high compared to the average national level, indicating that to be successful as a trader some good notions of accounting and arithmetic, often only taught in schools, are needed. The education level is in both countries higher for rice than for tomato traders.

In India, all surveyed traders were retailers, but $7 \%$ of the rice retailers and $1 \%$ of the tomato retailers also considered themselves as wholesalers in addition. There were no significant price differences noted between wholesalers and retailers in India, neither for rice, nor for tomato. In contrast, in Madagascar, $32 \%$ of the rice traders and $25 \%$ of the tomato traders were wholesalers, offering significantly lower prices than retailers.

Rice traders seem to run significantly "bigger" businesses than tomato traders, in India as well as in Madagascar: the quantities sold, their storage capacity, the value of business vehicles, as well as their working capital are much higher. This holds even if we look at the retailers in the sample only. In line with results by Minten et al. (2010), we find that, while street sellers are important for the distribution of fresh fruits and vegetables, their turnover is often less than that of traders that operate out of wet markets: in India, the former sell on average $87 \mathrm{~kg}$ of tomatoes per week, as compared to $188 \mathrm{~kg}$ per week for the latter. In Madagascar, the corresponding figures are $118 \mathrm{~kg}$ and $200 \mathrm{~kg}$ respectively. 
In India, we observe strong differences in retail shop formats between the different commodities concerned, in line with earlier findings from a case study in Delhi (Minten et al., 2010). An overview of the different formats as well as of their relative frequency is presented in Table 1. While tomato sellers in India are often mobile, with a push cart that allows them to go from house to house, most of the tomato sellers in Madagascar are not mobile.

\section{Results}

This section presents the results of our quantitative analysis of the availability of quality at food markets in the two countries under study. In addition, it discusses the observed differences in quality premiums in these markets.

\subsection{Availability of quality products}

To make cross-country comparisons of quality meaningful, we stick to a few simple, easily comparable indicators, which came out during pre-testing to be important for quality, i.e. grain length, brokenness, impurity by stones and by paddy husks in the case of rice, and size, degree of rottenness, and the presence of black spots in the case of tomatoes. ${ }^{4}$ Table 2 shows the availability of the different qualities at the different retail outlets in the two countries. For most of the characteristics, the bulk of the observations belong to the highest quality category, in India as well as Madagascar. An exception is the size of tomatoes, where most of the tomatoes are of medium size. If we compare the shares of the highest quality categories, India scores best for each of the indicators, except for grain length of rice.

\footnotetext{
${ }^{4}$ For example, the different quality categories for rice grain length were defined as "round", "medium", or "long", which are widely used characteristics of rice in these markets; the categories for degrees of brokenness are "high ( $>15 \%$ broken)", "medium (5-15\% broken)", and "low ( $<5 \%$ broken)." In the survey setup, we made sure to minimize the leeway for subjective interpretation of the quality attributes and examples of different qualities were shown to the enumerators. While there was arguably some variation in these quality attributes according to local settings or varieties observed in India and Madagascar, our pilot surveys did not suggest that the quality attributes would be interpreted very differently across countries in a way that would affect our results. For example, long grain rice is perceived to be of a higher quality in both countries, as seen from the signs on the relative attribute values in Table 3.
} 
We use a Chi-square test to formally test whether the availability of different qualities differs between India and Madagascar. The results confirm that the frequency distribution of the different qualities is significantly different between the two countries. Madagascar scores significantly worse than India on availability of quality along 6 out of 7 dimensions, notably brokenness, impurities by stones and by paddy husks for rice, and degree of rottenness, presence of spots, and size for tomatoes. Only in the case of grain length does Madagascar have a higher availability of the highest quality category, i.e. long grain rice. ${ }^{5}$

\subsection{Price premiums for food quality}

Marginal prices of specific quality attributes cannot be directly observed from market transactions, as quality attributes are embedded in a single product. Hence, in order to estimate the value of quality attributes in these traditional market settings, we rely on two distinctive methods. The first is a stated preference method where values of attributes are reported by traders in response to open-ended elicitation questions; the second is a revealed preference method where price premiums for quality attributes are derived from a log-linear hedonic pricing regression model fitted to observed price and attribute variables. $^{6,7}$

\section{(a) Stated values of attributes}

In order to reduce hypothetical bias traders, rather than consumers, were surveyed, as the former are better informed about current prices, which may fluctuate from day to day. Trader-reported price data might more accurately reflect effective sales prices, as they are less dependent on customer-related idiosyncratic errors (e.g. in terms of market

\footnotetext{
${ }^{5}$ For a more general discussion of the characteristics of rice varieties available in Madagascar, see Fidelis et al. (1990).

${ }^{6}$ Our results are robust to a linear regression model specification.

7 Several authors have compared the usefulness of revealed versus stated preference methods. The general consensus is that revealed preference methods are more valid, as they reflect market discipline, whereas stated preference methods may be more useful for "out of range" predictions, i.e. estimations of values which are not directly observed in the market (Azevedo et al., 2003). Stated preference methods tend to overestimate real valuations, due to the hypothetical bias problem (e.g. Harrison and Rutström, 2008). However, in a review of existing evidence, Murphy et al. (2005) find the bias to be less important than commonly assumed, especially for the valuation of private goods. The hypothetical bias is also argued to be lower for respondents who are familiar with the good being valued (Harrison and Rutström, 2008).
} 
information). A similar approach is taken by Amegbeto et al. (2008). Each trader was asked to evaluate the price difference, ceteris paribus, for each of the quality attributes described in Section 4.1., comparing a better quality to a worse quality (Table 3). For example, we asked "What is the price differential of rice of long grain length compared to rice of medium grain length, everything else being equal?" To allow for cross-country comparison, the stated values in local currencies were then converted to US dollars per $\mathrm{kg}$ using prevailing exchange rates at the time of the survey. The analysis was carried out using the relative values of attributes (relative to the mean observed price in each country), but the results are robust (and even more significant) if we use absolute values.

In the case of rice, the stated value of each quality attribute is overall low in Madagascar. None of the quality attributes would increase the value of rice by more than $10 \%$ (Table 3). The highest values (resp. $8 \%$ and $9 \%$ ) are attached to a level of broken rice of below $5 \%$ and to the absence of small rock particles. We also find that the relative value of different quality attributes (compared to the average product price) is significantly higher for tomato than for rice. This hints at higher potential returns to quality improvements in tomato but it may also reflect the difference in perishability and shelf life between the two products. Rice can be stored for longer periods while tomato traders may need to offer large price reductions for low quality products in order to avoid a complete loss. There is a particularly high value attached to tomatoes that have no signs of rottenness: traders estimate the quality premium at almost $50 \%$ of the average tomato price in Madagascar.

Also in India, the highest quality premium is paid for tomatoes that are not rotten; the size of the premium is slightly higher but also around $50 \%$. Quality premiums for tomatoes are generally larger in India than in Madagascar (except for low vs. high level of rottenness), but they are still mostly of the same order of magnitude. On the other hand, there is a large difference in the size of quality premiums for rice between India and Madagascar. The average stated values of quality attributes for Indian rice are all well above $10 \%$ of the rice price. The highest values (around $45 \%$ of the rice price in 
India) are attached to a level of broken rice below $5 \%$ and to the absence of small rock particles in rice, as was the case for rice in Madagascar.

To formally test whether the stated values of attributes in India are higher than in Madagascar, t-tests were conducted on the average stated values (Table 3). ${ }^{8}$ The stated values of attributes are higher in India than in Madagascar for 12 out of 13 attributes. Similarly, the differences between averages are significant at a 5\% confidence level for 12 out of 13 attributes. As the stated values of attributes are the local traders' direct estimations of the quality premiums, we thus find that quality premiums are, except for 2 attributes out of 13, significantly higher in India.

\section{(b) Hedonic pricing}

Some respondents might have had difficulties to understand the concept of 'ceteris paribus', an important issue in the stated preference valuation literature (e.g. Murphy, 2005); especially as there may be some correlation between certain quality attributes. This implies that respondents may have faced difficulties in disentangling the separate contributions of single quality attributes which usually come "as a package" (Almond and Hausman, 1994). This issue is often referred to as the "embeddedness" problem.

To separate the values of attributes that are sold as a package, we rely on revealed preference methods. We collected data on the three most important types of rice or tomatoes that traders were selling, their physical characteristics, and the prices charged for these types on the day of the survey. The three types were then incorporated (with their respective prices) in our dataset as separate observations.

If we assume the marginal yield of these characteristics and the implicit price for each attribute constant, a hedonic price regression can be estimated where the food price is a function of characteristics of the product, through variety choices or post-harvest technologies. A simple model of the following form can then be run:

\footnotetext{
${ }^{8}$ The tested null hypothesis is $\mathrm{H}_{0}$ : Relative value of attribute in Madagascar = Relative value of attribute in India.
} 


$$
p_{h}=\sum_{k=0}^{N} \beta_{h}^{k} X_{h}^{k}+v
$$

where $p_{h}$ is the price of the product $h, X^{k}{ }_{h}$ is the quantity of attribute $k$ contained in product $h, \beta_{h}^{k}$ the implicit price, and $v$ a stochastic error term. Similar approaches have been used in case studies in developed and developing countries alike by e.g. Edmeades (2007), Lambert and Wilson (2003), Dalton (2004), Langyinto et al. (2004) and Fafchamps et al. (2008).

A hedonic regression of the $\log$ of the price per $\mathrm{kg}$ was thus run on quality attributes. The obtained coefficients show the rewards for these attributes. Table 4 shows the results of this regression as well as of a Chow test for significance of the difference in quality premiums between countries.

The coefficients from the hedonic price regression are in most cases larger in India than in Madagascar. However, the differences are only statistically significant (at the $10 \%$ level) in the case of rice with a degree of brokenness below 5\% (vs. high degree), and in the case of rice with long grain length (vs. medium length). For the former attribute, the absolute value of the premium in India is more than nine times larger than the one in Madagascar. For the latter, the India coefficient is almost 50 times larger than the Madagascar one.

Most quality attributes show relative price differentials of the same size order as in the stated preference method. For example, the quality premium calculated through hedonic pricing is similar in size to the stated quality premium in the case of rice with a medium degree of brokenness (a price difference of resp. 23\% and 18\% for India and 3\% for both methods in Madagascar $)^{9}$ Nevertheless, the stated quality premium for long grain length in India is more than ten times the quality premium calculated through hedonic pricing;

\footnotetext{
${ }^{9}$ Note that the correct interpretation of the coefficient $\beta$ of a dummy variable in a loglinear regression as a percentage change of the dependent variable is $\left(e^{\beta}-1\right) * 100$ - which can be approximated by $\beta^{*} 100$, especially at lower levels of $\beta$.
} 
and likewise for stone and paddy husk impurities. This might be a signal of the embeddedness problem mentioned above.

For tomatoes, even if the size of the coefficients is, as expected, higher (often double) in India than in Madagascar, the Chow test does not indicate any significant differences. This may be due to the lack of observations for low quality products in India: for example, there were no observations for tomatoes with a high degree of rottenness, and only 8 with a medium degree of rottenness.

Even if the results provided by the hedonic price regression are less supportive than those from the stated values of attributes method, they still suggest that, in the cases where the coefficients are significantly different from each other, it is the Indian coefficient which is highest, i.e. India has a higher quality premium.

\section{A tentative explanation}

In what follows, we develop a simple theory framework, based on income differences between countries, which can potentially explain the empirical observations described above. Before doing so, we first present a literature review on the link between food demand and income and then discuss evidence of the income gap between the two settings studied.

\subsection{Income and food demand - A literature review}

Existing empirical literature points out that with increasing incomes, consumers shift from less expensive, staple foods such as wheat and rice to more expensive foods such as fruits and vegetables, meat and dairy (see e.g. Ye and Taylor, 1995 for China; Sahn, 1988 for Sri Lanka; Joshi et al., 2007 and Ito et al., 1989 for several studies on South Asia and Asia respectively). There is however less evidence on how income growth affects demand for different varieties (of different quality levels) within a particular food commodity. We review that literature below. 
Most studies on the demand for search attributes ${ }^{10}$ ignore the link with consumer income (e.g. Amegbeto et al., 2008; Langyintuo et al., 2004). Exceptions are, for example, Mergenthaler et al. (2009) who find that income is a significant determinant of consumers' willingness to pay extra for food safety guarantees for vegetables and for convenience attributes (notably, potatoes which are washed, peeled, pre-cut, packed and cooled) in Vietnam. Demont and co-authors show that individual income correlates positively with the price premium Beninese consumers are willing to pay for higherquality (parboiled) rice (Demont et al., 2012), but they fail to find an effect of individual incomes on quality premiums in Senegal (Demont et al., 2013). Interestingly, in Benin, price premiums consumers are willing to pay range from 9-34\%; whereas in Senegal, where average income of the participants in the experimental auction is three times higher than in the Beninese experiment, quality premiums range from 34-44\%. Admittedly, as the premiums are for very different quality attributes, these figures are hard to compare.

Those studies which take into account consumer income usually focus on credence attributes, such as organic or environmentally-friendly food (e.g. Blend and van Ravenswaay, 1999) and fair-trade goods (e.g. Howard and Allen, 2008). ${ }^{11}$ Contrary to the widely perceived view that higher income leads to a higher willingness-to-pay for quality, Howard and Allen (2008) find that higher income groups are willing to pay less for a "domestic fair trade" label, guaranteeing better wages and health conditions for domestic workers. In the study by Blend and van Ravenswaay (1999), income does also not seem to have a significant effect on the probability of buying eco-labeled products. A possible explanation may be that the direct consumer benefits of these credence attributes are less obvious and more subject to personal beliefs and ideologies.

\footnotetext{
${ }^{10}$ Broadly speaking, the literature distinguishes three categories of quality attributes in a food product (Nelson, 1970; Caswell and Mojduszka, 1996): "search" attributes are quality attributes which are directly observable, as consumers can inspect goods and obtain full information on their quality prior to purchasing them; "experience" attributes are quality attributes which are only observable after purchase, through consumption; finally, "credence" attributes are quality aspects which remain unobserved, even after purchase (e.g. production according to specific environmental or social standards).

${ }^{11}$ Most of these studies use stated preference methods and hence do not directly observe consumer decisions.
} 
Yu and Abler (2009) use Chinese panel data to estimate a regression of unit values for specific food groups on household characteristics such as income, assets, household size, and education, echoing a methodology proposed by Deaton (1988). They find that rising household incomes lead to significantly higher unit values for staple foods as well as for high-value foods, suggesting an increased demand for quality. However, both $\mathrm{Yu}$ and Abler (2009) and Deaton (1988) lack directly observed unit prices; they use the ratio of expenditures over quantity for each food group as a proxy.

Stevens and Winter-Nelson (2008) relate an indirect measure of consumer income, in particular the frequency with which they eat meat, to their willingness to trade local white maize varieties for a novel variety of bio-fortified yellow maize. While bio-fortification is clearly a positive "credence" quality attribute, the organoleptic characteristics associated with bio-fortification are usually less preferred than those of traditional white maize varieties. The results of the study show that poorer consumers are more likely to accept bio-fortified maize than richer consumers.

Finally, Schipmann and Qaim (2011) find that market formats catering to poor consumers (such as wet markets) have fewer vegetables with high-quality search attributes on offer than supermarkets catering to better-off consumers in Bangkok. This finding is in line with earlier results by Minten and Reardon (2008) for Madagascar and Figuié and Moustier (2009) for Vietnam. Interestingly, Minten et al. (2010) find that modern retailers in Delhi have in general lower quality on offer than traditional retailers; but they argue that this could be due to "infancy problems" with logistics given the recent arrival of modern retail in Delhi.

In general, we find that the literature on the analysis of the income elasticity of the demand for quality within a particular food commodity is thin and stands in stark contrast with other strands of the literature. Research on consumer durables, for example, has shown that with income growth, consumers do switch from low-quality to high-quality varieties of the same product (e.g. Bils and Klenow, 2001; Gabszewicz and Thisse, 1979). 


\subsection{Income differences between Madagascar and India}

While the two surveyed countries are both poor, Madagascar is considerably behind India. Madagascar is a poor economy by any measure. It was estimated to have a nominal per capita GDP of only 392\$ in 2007 and it was ranked $163^{\text {rd }}$ out of a total of 179 countries by the IMF, based on per capita GDP calculations at purchasing power parity in 2007. Different national household surveys between 1993 and 2005 have evaluated poverty headcount ratios to be around $70 \%$. India is a developing economy which is rapidly growing. It was ranked $129^{\text {th }}$ in the same lists by the IMF and had a nominal per capita GDP of $942 \$$ in 2007 . The poverty headcount ratio in India in 2005 was evaluated at $27 \%$.

These differences at the national level are also reflected in the income data for the two cities where the survey was fielded. In Antananarivo, the capital of Madagascar, annual per capita consumption expenditures are estimated at 500,693 Ar or 250 US\$ in $2006 .^{12}$ The annual per capita consumption expenditure in Dehradun, based on government surveys, is estimated to be around $21,618 \mathrm{Rs}$, or $546 \mathrm{US} \$ .^{13}$ So, the average income level in Dehradun is estimated to be at least twice as high as in Antananarivo.

Such income differences matter for food demand - and hence for the demand of the two crops under consideration, as shown by several empirical demand studies. In the case of Madagascar, Ravelosoa et al. (1999) find based on national consumption surveys that income elasticities of the demand for rice and vegetables are as high as 0.47 and 1.18 respectively. In the case of India, Mittal (2006) shows income elasticities for the cereals category and for the fruits and vegetables category are 0.17 and 0.72 respectively. These results illustrate two important points of empirical demand analysis in developing

\footnotetext{
${ }^{12}$ This estimate for annual per capita consumption expenditure applies to the urban region of Analamanga, which broadly corresponds to Antananarivo, and is provided by INSTAT (2006).

${ }^{13}$ This estimate applies to the city of Dehradun and is provided by the Urban Development Department of the Government of Uttarakhand (2007), whereas the average household size has been inferred from the ratio of income per household to income per capita.
} 
countries (e.g. Timmer et al., 1983). First, income is an important determinant of food demand within a country; and a doubling of income leads to increases in demand for these crops in the two countries between $17 \%$ and $118 \%$. Second, income elasticities for these food products are significantly lower in the richer country (India) as compared to the poorer one (Madagascar). This is consistent with existing literature which finds that income elasticities of food demand decline with increasing incomes; and that income elasticities of demand for high-value products such as vegetables are higher than for staples such as cereals (e.g. Pinstrup-Andersen and Caicedo, 1978; Park et al., 1996).

\subsection{A theoretical model}

Given the large income differences between the two cities/countries under study and given the importance of income in empirical food demand studies, we build a theoretical model with income as a driver for changes in demand for quality between countries. We draw on Lancaster's (1966) classical approach that considers a product as a bundle of characteristics, which consumers derive utility from. His consumer demand model has been developed further and linked to a supply model in later research work (e.g. Hendler, 1975; Lucas, 1975; Ladd and Suvannunt, 1976; Rosen, 1974).

Our framework is a reduced form model in which the availability of quality and its price are endogenously determined. It is close to Lucas' (1975) and Rosen's (1974) model in that it combines a demand and supply model through a market clearing equation. However, it is different from their approach as it does not assume away spillovers between the production of different qualities. More in line with agricultural production realities, producers choose a level of technology which determines their product mix of varieties with low and high organoleptic quality attributes. Moreover, we establish an explicit link between the income level and the utility which can be derived from higher quality products (which come at a higher price). ${ }^{14}$

\footnotetext{
${ }^{14}$ It is quite intuitive to assume that the marginal rate of substitution between (remaining) income and quality is higher at low levels of income, if marginal returns to income are decreasing. For reasons of simplicity, we assume that utility is linearly increasing in remaining income; but the same results can be shown to hold if utility is concavely increasing in remaining income (see also footnote 16).
} 
In line with Gabszewicz and Thisse (1982), we assume a population of identical consumers with identical income $R^{*}{ }^{15}$ When shopping for food, these consumers have the choice between two products: a "high quality" product A with price $p_{A}$, and a "low quality" product B, priced at $p_{B}$. Every consumer buys at most one product and purchases are indivisible. All consumers have identical preferences, defined by the following utility functions:

$$
\begin{gathered}
U(0, R)=u_{0} R \\
U\left(A, R-p_{A}\right)=u_{A} R-p_{A} \\
U\left(B, R-p_{B}\right)=u_{B} R-p_{B},
\end{gathered}
$$

whereas $u_{A}>u_{B}>u_{0}>0$, and $U(0, R)$ is the utility of having neither a unit of A, nor of $\mathrm{B}$, and hence a remaining income $\mathrm{R} ; U\left(A, R-p_{A}\right)$ is the utility of having a unit of $\mathrm{A}$ and a remaining income $R-p_{A}$, and likewise for $U\left(B, R-p_{B}\right)$. If we keep the remaining income constant, product $\mathrm{A}$ is preferred to $\mathrm{B}$; and both are preferred to having no product at all. $^{16}$

A consumer with income $R^{*}$ will choose to buy no product at all if:

$U\left(0, R^{*}\right)>U\left(B, R^{*}-p_{B}\right)$, which can be rewritten as $u_{0} R^{*}>u_{B} R^{*}-p_{B}$, and

$U\left(0, R^{*}\right)>U\left(A, R^{*}-p_{A}\right)$, which can be rewritten as $u_{0} R^{*}>u_{A} R^{*}-p_{A}$, or

a consumer will not buy any of the products if

$$
p_{A}>\left(u_{A}-u_{0}\right) R^{*} \text { and } p_{B}>\left(u_{B}-u_{0}\right) R^{*}
$$

i.e. if the product price of product A (resp. B) is too high, if the extra utility derived from consuming one unit of A (resp. B) is not enough to compensate for its cost, or if the income of the consumer is too low. A consumer will buy a high quality product A rather than a low quality product $B$ if:

15 A major difference between our model set-up and the usual set-up in related papers including Gabszewicz and Thisse (1982), Accharya (1998), and Mussa and Rosen (1978), is that these usually assume that (a) there are different consumer types in one market, while we look at different markets, but each with a "representative consumer" at the average income level; (b) firms act as monopolies or as competitors, but if they are competing, each firm is producing a product of a different quality, while we consider a competitive market in which each supplier is producing a similar mix of different qualities, through a technology constraint which is typical to the agricultural context.

${ }^{16}$ The same results can be shown to hold for a more general specification of the utility function, such as e.g. the one proposed by Tirole (1988: 97), where $U=u\left(R-p_{i}\right)+\Phi\left(s_{i}\right)$ for $i=A, B$ and $s_{i}$ the quality level of the good consumed, with $s_{A}>s_{B}$ and $p_{A}>p_{B}$, as long as $u$ is linearly or concavely increasing in $R$ and $\Phi$ increasing in $s$. 


$$
\begin{gathered}
U\left(A, R^{*}-p_{A}\right)>U\left(B, R^{*}-p_{B}\right), \text { or } \\
p_{A}-p_{B}<\left(u_{A}-u_{B}\right) R^{*}
\end{gathered}
$$

The supplier can choose between different technologies. A technology $T_{\alpha}$ results in a product mix with a share $\alpha$ of product $A$ and a share $(1-\alpha)$ of product $B$. In line with earlier work by, amongst others, Rosen (1974) and Accharya (1998), we assume the production cost under a specific technology is a quadratic function of $\alpha: c(\alpha)=C_{0}+C \alpha^{2}$. An important feature of a quadratic cost function is that the marginal cost of raising $\alpha$ increases with $\alpha .{ }^{17}$ This corresponds to Caswell and Mojduszka (1996)'s finding that the supply of food quality is subject to rising marginal costs. Below, we will show that both $p_{A}$ and $\alpha$ are a function of $R$ in equilibrium.

We assume a competitive environment, in which the supplier's profit margin is zero. The price at which he sells his product mix, then equals the production cost for that product mix:

$$
\alpha(R) p_{A}(R)+(1-\alpha(R)) p_{B}=C_{0}+C \alpha^{2}(R)
$$

For $\alpha=0$, the supplier will sell only low quality product $\mathrm{B}$ and his production cost is $C_{0}$. As a result, $p_{B}$ will be such that $p_{B}=C_{0}$.

The price of the high quality product will be determined by the market clearance condition. The market will clear, hence both low and high quality products will be bought, if the quality premium $\left(\theta=p_{A}-p_{B}\right)$ exactly adjusts to the difference in utility which consumers derive from consumption of product $\mathrm{A}$ and $\mathrm{B}:{ }^{18}$

$$
p_{A}(R)=p_{B}+\left(u_{A}-u_{B}\right) R
$$

Finally, the product mix on the market is determined by the zero-profit condition. In particular, combining (1) and (2) yields

\footnotetext{
${ }^{17}$ The mere disposal of low quality products could as well (in a broad sense) be seen as a "technology": it decreases the share of low quality items, and increases the production cost of high quality items.

${ }^{18}$ In contrast with the work by Mussa and Rosen (1978) and others on strategic pricing by a monopsonist or strategic behaviour in a duopsony context (e.g. Gabszewicz and Thisse, 1979; Wauthy, 1996), but in line with Rosen (1974), we assume pure competition, which is a more realistic assumption for the markets under study.
} 


$$
p_{B}+\alpha(R)\left(u_{A}-u_{B}\right) R=C_{0}+C \alpha^{2}(R)
$$

And, as $p_{B}=C_{0}$,

$$
\alpha(R)\left(u_{A}-u_{B}\right) R=C \alpha^{2}(R)
$$

This equation has two solutions: a corner solution $\alpha(R)=0$, and an inner solution,

namely $\alpha(R)=\frac{1}{C}\left(u_{A}-u_{B}\right) R$. Hence, either there is no quality differentiation at all, or suppliers sell a share of high quality products that is determined by the representative consumer's income.

Based on equations (1) and (2), we derive two propositions:

Proposition 1: The quality premium observed in a high income economy is higher than in a low income economy.

\section{Proof:}

The higher the additional utility which consumers derive from product $\mathrm{A}$, compared to product $\mathrm{B}$, and the higher the income $R^{*}$ of the representative consumer, the higher $\theta$ will be:

$$
\frac{\partial \theta}{\partial R}=\frac{\partial\left(p_{A}-p_{B}\right)}{\partial R}=\frac{\partial\left(u_{A}-u_{B}\right) R}{\partial R}=u_{A}-u_{B}>0
$$

Hence, not only will consumers in the high-income country buy foods of higher quality and higher prices; our model also predicts that the price differential between high- and low-quality varieties will increase with income.

Proposition 2: Suppliers in a high income economy will choose to offer a higher share of high quality food products than in a low income economy.

\section{Proof:}

$$
\frac{\partial \alpha}{\partial R}=\frac{\left(u_{A}-u_{B}\right)}{C}>0
$$

Note that the share of high quality products is expected to increase faster with income if the extra utility consumers derive from a high quality product is higher. 
Our model predicts that if there is technological progress with growing incomes, such that $C$ declines, the quantity of high quality products $(\alpha)$ on offer will further increase, as it becomes cheaper to produce them. However, in our model, this will not affect quality premium $\theta$, as the latter is determined by the necessity to clear the market through consumption of all products, which means prices are determined by consumer relative preferences for both products, which are in turn determined by consumer income. Note that, if a supplier would offer high-quality product A at a cheaper price, consumers will prefer product A and product B would remain unsold.

\section{Conclusions}

In this paper, we empirically explore the difference in the supply of food quality and its pricing between India and Madagascar, two countries that are both poor but at different stages of development. Both markets are unregulated with respect to quality. We find that food quality on offer and quality premiums are significantly lower in Madagascar. We subsequently present a simple theoretical framework that offers a plausible explanation for these stylized facts solely based on important income differentials that exist between both economies: average incomes are about twice as high in India as in Madagascar. In our model, the transformation towards a high-quality food economy is driven by an endogenous shift in consumer demand. Interestingly, no regulations on quality standards are present in our model as a driver for the transformation of food markets; higher-quality food is just delivered because of the increasing demand and willingness to pay. In particular, in our model, quality premiums adjust to relative demand for different food qualities, based on the requirements that markets should clear for all qualities. The relative supply of quality is in turn determined by the returns to quality and the cost of producing it.

While our empirical findings are in line with the theoretical model we propose, they do not offer conclusive evidence for our tentative explanation. As is usually the case with theoretical models, we rely on a set of simplifying assumptions and reality could be more 
complex. There could be other plausible explanations for our empirical findings as well, such as differences in income dispersion, in technologies, or in institutional settings in which the markets operate. We have assumed in our model that consumer preferences are the same across different markets, and that it is only consumer demand which varies as a function of income. Clearly, in countries as different as Madagascar and India one could argue that consumer preferences for quality are different as well, for example because of differences in cuisine and cooking habits. It seems that further research is needed to confirm whether we can replicate these results in markets in more comparable settings. ${ }^{19}$

Likewise, other factors such as capital constraints, transaction costs, the agricultural production structure, policies and institutions could affect the supply of food quality (see e.g. Vandemoortele et al., 2012). So far, these determinants have received little attention in food demand models, theoretically and empirically (e.g. Deaton and Muellbauer, 1980). Exploring the relative contributions of these factors, in particular to the supply of food quality, remains fertile ground for future research.

The provided interpretation might however be plausible, especially given that similar observations have been made for other commodities as well (e.g. Bils and Klenow, 2001). We discuss a number of considerations emerging from this research. First, in those markets where the demand and willingness to pay for quality are higher, returns to public investment supporting the adoption of varieties with superior quality characteristics will be higher as well. If, in line with our model, there is a lower willingness to pay for high quality in poorer economies, the highest pay-off for food technology development will likely be in productivity-increasing or input cost-reducing varieties in such settings, seemingly supporting current priorities of agricultural research in these countries, which focus mainly on maximizing agricultural output and reducing input costs (e.g. Von Braun et al. 2008).

\footnotetext{
${ }^{19}$ One would need to find a way, however, to avoid the influence from spillovers between demand patterns by consumers of different income levels present in the same market.
} 
Second, if we are able to better predict in which markets demand for quality will grow, it will be easier to identify new market opportunities and market transformation. The existing literature shows (in line with our model's predictions) that the growth of modern retail, which usually focuses on higher-quality products, is slower in poor than in relatively richer economies (World Bank, 2007). For example, while modern retail has been present for over a decade in Madagascar, it has not been able to capture a large share of the food retail market (Minten, 2008). In India, on the other hand, modern food retail has expanded at annual growth rates of around $50 \%$ over the past decade, one of the fastest rates in history (Reardon et al., 2010).

Better insights in these issues can also support the identification of improved market development strategies. For example, if consumer demand for high-quality commodities expands, local institutional settings in which markets operate are crucial determinants of whether local supply chains can respond to this demand so that local farmers can benefit from these demand shifts; or whether consumers will instead revert to imported products to satisfy their new demands. In China, for example, consumers are increasingly concerned about, and willing to pay for food safety in milk powder; but mistrust in local institutions leads them to prefer imported milk powder (e.g. Lafougère, 2013). In Senegal, Demont and Rizzotto (2012) show that rich consumers prefer imported rice for its superior quality characteristics as compared to local rice. With the right set of institutions and incentives, local farmers may as well be able to produce high quality food products at the price consumers are willing to pay.

Finally, in view of the ongoing debates on food demand projections and their implications for future food prices, a correct estimation of demand systems which takes into account quality differentials within commodities seems important in generating correct food market projections and analysis. The presence of a possible positive income elasticity of the demand for quality seems especially important for rice, a major staple in both Africa and Asia, but that characteristic is currently mostly ignored in empirical demand analysis. 


\section{References}

Accharya, R. (1998) Monopoly and product quality: Separating or pooling menu? Economics Letters, 61: 187-194.

Almond, P.A., Hausman, J.A. (1994), Contingent valuation: Is some number better than no number, Journal of Economic Perspectives, 8(4): 45-64.

Amegbeto, N.K., Manyong, V.M., Coulibaly, O., Asiedu, R. (2008) Estimating market demand for fresh yam characteristics using contingent valuation: implications for crop breeding and production choices. Agricultural Economics, 39(3): 349-363.

Azevedo, C.D., Herriges, J.A., Kling, C.L. (2003) Combining revealed and stated preferences: consistency tests and their interpretations. American Journal of Agricultural Economics, 85(3): 525-537.

Bils, M. and Klenow, P. (2001) Quantifying Quality Growth. American Economic Review, 91(4): 1006-1030.

Blend, J.R., van Ravenswaay, E.O. (1999) Measuring consumer demand for ecolabeled apples. American Journal of Agricultural Economics, 81(5): 1072-1077.

Bowbrick, P. (1982) The Economics of Grades. Oxford Agrarian Studies, 11: 65-92.

Caswell, J.A., Mojduszka, E.M. (1996) Using informational labeling to influence the market for quality in food products. American Journal of Agricultural Economics, 78(5): 1248-1253.

Dalton, T.J. (2004), A household hedonic model of rice traits: economic values from farmers in West Africa, Agricultural Economics, 31: 149-159

Deaton, A. (1988), Quality, quantity and spatial variation of price, American Economic Review 78(3):418-430.

Deaton, A., Muellbauer, J. (1980) Economics and consumer behavior. Cambridge University Press.

Demont, M. Zossou, E., Rutsaert, P., Ndour, M., Van Mele, P., Verbeke, W. (2012) Food Quality and Preference, 23: 63-70.

Demont, M., Rizzotto, A.C. (2012) Policy sequencing and the development of rice value chains in Senegal. Development Policy Review, 30(4): 451-472.

Demont, M., Rutsaert, P., Ndour, M., Verbeke, W., Seck, P.A., Tollens, E. (2013) Experimental auctions, collective induction and choice shift: willingness-to-pay 
for rice quality in Senegal. European Review of Agricultural Economics, 40(2): 261-286.

Edmeades, S. (2007), A hedonic approach to estimating the supply of variety attributes of a subsistence crop, Agricultural Economics, 37(1): 19-28

Fafchamps, M., Vargas-Hill, R., Minten, B., (2008) Quality Control in Non-Staple Food Markets: Evidence from India. Agricultural Economics, 38: 251-266.

Fidelis, A., Francois, R., Roland, R., Juliano, B.O., Perez, C.M., Flinn, J.C. and Shahi, B.B. (1990) Grain quality characteristics of rice in Madagascar retail markets. Plant Foods for Human Nutrition, 40: 21-30.

Figuié, M., Moustier, P. (2009) Market appeal in an emerging economy: supermarkets and poor consumers in Vietnam. Food Policy, 34: 201-217.

Gabszewicz, J., Thisse, J.F. (1982), Product differentiation with income disparities: an illustrative model. The Journal of Industrial Economics, 31(1/2): 115-129.

Government of Uttarakhand (2007) City Development Plan: Dehradun Revised. Under Jawaharlal Nehru National Urban Renewal Mission. Urban Development Department, Government of Uttarakhand.

Harrison, G.W., Rutström, E.E. (2008), Experimental evidence on the existence of hypothetical bias in value elicitation methods. In: Plott, C.R. and Smith, V.L. (eds.) Handbook of Experimental Economics Results (first edition). Vol. 1. North Holland: Elsevier.

Harriss-White, B. (1999), Agricultural markets from theory to practice: Field experiences in developing countries, St. Martin's Press, New York

Hendler, R. (1975) Lancaster's new approach to consumer demand and its limitations. American Economic Review, 65(1): 194-199.

Howard, P.H., Allen, P. (2008) Consumer willingness to pay for domestic 'fair trade': Evidence from the United States. Renewable Agriculture and Food Systems, 23(3): 235-242.

INSTAT (2006) Enquête périodique auprès des ménages 2005, Rapport principal, Sécretariat Général, Ministère de l'Économie, des Finances et du Budget, Madagascar. 
Ito, S., Peterson, E.W.F., Grant, W.R. (1989) Rice in Asia: is it becoming an inferior good? American Journal of Agricultural Economics, 71(1): 32-42.

Joshi, P.K., Gulati, A., Birthal, P.S. (2007) Agricultural diversification in India: Status, Nature and Pattern. In: Joshi et al. (eds.) Agricultural diversification and smallholders in South Asia. New Delhi: Academic Foundation.

Ladd, G.W., Suvannunt, V. (1976) A model of consumer goods characteristics. American Journal of Agricultural Economics, 58(3): 504-510.

Lafougère, C. (2013) Global development in the infant formula sector. Seminar at the EUCOLAIT General assembly in Helsinki, 2013.

Lambert, D.K., Wilson, W.W. (2003), Valuing varieties with imperfect output quality measurement, American Journal of Agricultural Economics, 85(1): 95-107

Lancaster, K.J. (1966) New approach to consumer theory. Journal of Political Economy, 74: $132-157$.

Langyintuo, A.S., Ntoukam, G., Murdock, L., Lowenberg-DeBoer, J., Miller, D.J. (2004), Consumer preferences for cowpea in Cameroon and Ghana, Agricultural Economics, 30: 203-213

Lucas, R.E.B. (1975) Hedonic price functions. Economic Inquiry, 13(2): 157-178.

Mergenthaler, M., Weinberger, K., Qaim, M. (2009) Consumer valuation of food quality and food safety attributes in Vietnam. Review of Agricultural Economics, 31(2): 266-283.

Minten, B. (2008), The food retail revolution in poor countries: Is it coming or is it over?, Economic Development and Cultural Change, 56(4): 767-789

Minten, B., Reardon, T. (2008) Food prices, quality, and quality's pricing in supermarkets versus traditional markets in developing countries. Review of Agricultural Economics, 30(3): 480-490.

Minten, B., Reardon, T., Sutradhar, R. (2010), Food prices and modern retail: The case of Delhi, World Development, 38(12): 1775-1787

Mittal, S. (2006) Structural shift in demand for food: Projections for 2020, Working paper no. 184, ICRIER, New Delhi 
Murphy, J.J., Allen, P.G., Stevens, T.H., Weatherhead, D. (2005), A Meta-Analysis of hypothetical bias in stated preference valuation, Environment and Resource Economics, 30: 313-325

Mussa, M., Rosen, S. (1978) Monopoly and Product Quality. Journal of Economic Theory, 18: 301-317.

Nelson, P. (1970) Information and consumer behaviour. Journal of Political Economy, 78(2): 311-329.

Park, J.L., Holcomb, R.B., Raper, K.C., Capps, O. Jr. (1996) A Demand Systems Analysis of Food Commodities by U.S. Households Segmented by Income. American Journal of Agricultural Economics, 78(2): 290-300.

Pingali, P. (2004). Westernization of Asian Diets and the Transformation of Food Systems: Implications for research and policy, Working Papers 04-17, FAO Agricultural and Development Economics Division, Rome.

Pinstrup-Andersen, P. and E. Caicedo (1978). The Potential Impact of Changes in Income Distribution on Food Demand and Human Nutrition. American Journal of Agricultural Economics, 60(3): 402-415.

Ravelosoa, R., S. Haggblade, and H. Rajemison (1999). Estimation des Elasticites de Demande Madagascar a Partir d'un Modele AIDS. CFNPP Working paper no. 99, New York: Cornell University.

Reardon, T., and Timmer, C.P. (2007). Transformation of Markets for Agricultural Output in Developing Countries Since 1950: How Has Thinking Changed? In R.E. Evenson, and P. Pingali (Eds). Handbook of Agricultural Economics, 3: Agricultural Development: Farmers, Farm Production and Farm Markets (pp. 2808-2855). Amsterdam: Elsevier Press.

Reardon, T., Timmer, P., Barrett, C., Berdegué, J. (2003), The rise of supermarkets in Africa, Asia, and Latin America, American Journal Agricultural Economics, 85(5): 1140-1146.

Reardon, T., Timmer, P., Minten, B. (2010), The supermarket revolution in Asia and emerging development strategies to include small farmers, Proceedings of the National Academy of Science, December issue. 
Rosen, S. (1974), Hedonic prices and implicit markets: product differentiation in pure competition. Journal of Political Economy, 82: 34-55.

Sahn, D.E. (1988) The effect of price and income changes on food-energy intake in Sri Lanka. Economic Development and Cultural Change, 36(2): 315-340.

Schipmann, C., Qaim, M. (2011) Modern food retailers and traditional markets in developing countries: comparing quality, prices, and competition strategies in Thailand. Applied Economic Perspectives and Policy, 33(3): 345-362.

Stevens, R., Winter-Nelson, A. (2008) Consumer acceptance of provitamin A-biofortified maize in Maputo, Mozambique. Food Policy, 33: 341-351.

Swinnen, J. (ed.) (2007), Global supply chains, standards and the poor, CABI Publishing

Timmer, P., Falcon, W., Pearson, S. (1983) Food Policy Analysis, World Bank/John Hopkins University Press, Baltimore

Tirole, J. (1988) The Theory of Industrial Organization. Cambridge, Massachussets: MIT Press.

Unnevehr, L.J. (1986), Consumer demand for rice grain quality and returns to research for quality improvement in Southeast Asia. American Journal of Agricultural Economics, 68: 634-641.

Vandemoortele, T., Rozelle, S., Swinnen, J.F.M., and Xiang, T. (2012) Quality and Inclusion of Producers in Value Chains: A theoretical note. Review of Development Economics, 16(1): 122-136.

von Braun, J., Fan, S., Meinzen-Dick, Rosegrant, R. M. W., Ninn Pratt, A. (2008) International Agricultural Research for Food Security, Poverty Reduction, and the Environment: What to Expect from Scaling Up CGIAR Investments and "Best Bet" Programs, IFPRI, Washington.

Wauthy, X. (1996) Quality Choice in Models of Vertical Differentiation. Journal of Industrial Economics, 44(3): 345-53.

World Bank (2005), Food safety and agricultural health standards: Challenges and opportunities for developing countries' exports, World Bank, Washington DC.

World Bank (2007), World Development Report 2008: Agriculture for development, World Bank/Oxford University, Washington DC. 
Ye, S.T., Taylor, J.E. (1995), The impact of income growth on farm household nutrient intake: a case study of a prosperous rural area in Northern China. Economic Development and Cultural Change, 43(4): 805-819.

Yu, X., Abler, D. (2009), The demand for food quality in rural China. American Journal of Agricultural Economics, 91(1): 57-69. 
Tables

Table 1: Sample descriptives

\begin{tabular}{|c|c|c|c|c|c|c|c|c|c|}
\hline & \multirow{3}{*}{ Unit } & \multicolumn{4}{|c|}{ Madagascar } & \multicolumn{4}{|c|}{ India } \\
\hline & & \multicolumn{2}{|c|}{ Rice } & \multicolumn{2}{|c|}{ Tomato } & \multicolumn{2}{|c|}{ Rice } & \multicolumn{2}{|c|}{ Tomato } \\
\hline & & Mean & St. dev & Mean & St. dev. & Mean & St. dev & Mean & St. dev. \\
\hline \multicolumn{10}{|l|}{ Socio-economic information } \\
\hline age & years & 35.6 & 10.1 & 35.3 & 11.1 & 37.5 & 9.1 & 32.8 & 10.6 \\
\hline education & years & 9.1 & 3.0 & 6.9 & 2.7 & 11.9 & 2.3 & 5.8 & 3.9 \\
\hline gender & $1=$ male & $42 \%$ & & $29 \%$ & & $100 \%$ & & $100 \%$ & \\
\hline time in this business & years & 7.1 & 6.7 & 9.0 & 7.4 & 13.6 & 8.7 & 7.0 & 6.6 \\
\hline \multicolumn{10}{|l|}{ Business information } \\
\hline quantities sold in a week & ton & 1.23 & 1.94 & 0.65 & 1.28 & 1.92 & 5.83 & 0.59 & 0.30 \\
\hline maximum storage capacity & ton & 3.40 & 5.98 & 0.96 & 1.86 & 3.67 & 13.24 & 0.16 & 0.23 \\
\hline value vehicles in business & US\$* & 387 & 3394 & 44 & 508 & 1071 & 1857 & 162 & 305 \\
\hline working capital & US\$* & 274 & 558 & 124 & 368 & 208 & 454 & 37 & 73 \\
\hline number of traders known & number & 6.0 & 5.6 & 4.6 & 4.4 & 19.0 & 12.3 & 15.7 & 13.3 \\
\hline retail-cum-wholesale trader & $1=$ yes & $0 \%$ & & $0 \%$ & & $7 \%$ & & $1 \%$ & \\
\hline \multicolumn{10}{|l|}{ Type of business } \\
\hline wholesaler & $\%$ & 32 & & 25 & & & & & \\
\hline retailer with table & $\%$ & 53 & & 61 & & & & & \\
\hline streetseller & $\%$ & 0 & & 14 & & & & & \\
\hline shop (epicerie) & $\%$ & 15 & & 0 & & & & & \\
\hline Specialized cereals \& pulses store & $\%$ & & & & & 9 & & & \\
\hline Specialized rice shop & $\%$ & & & & & 3 & & & \\
\hline Kirana store with multiple products & $\%$ & & & & & 85 & & & \\
\hline Ration shop (PDS) & $\%$ & & & & & 3 & & & \\
\hline Retailer fixed location without covered shop & $\%$ & & & & & & & 8 & \\
\hline Retailer fixed location with covered shop & $\%$ & & & & & & & 24 & \\
\hline Push cart retailer fixed location & $\%$ & & & & & & & 50 & \\
\hline Push cart retailer no fixed location & $\%$ & & & & & & & 17 & \\
\hline Observations & number & 235 & & 205 & & 151 & & 157 & \\
\hline
\end{tabular}


Table 2: Availability of good quality products

\begin{tabular}{|c|c|c|c|c|c|}
\hline & & Availab & & Chi2 & 2-test* \\
\hline & & $\begin{array}{r}\text { Madagascar } \\
\% \\
\end{array}$ & $\begin{array}{r}\text { India } \\
\% \\
\end{array}$ & Chi2 & Pr. $>$ chi 2 \\
\hline Rice & & & & & \\
\hline$\%$ broken & a high level $(>15 \%)$ & 0.45 & 2.21 & & \\
\hline & a medium level & 19.79 & 17.88 & & \\
\hline & a low level $(<5 \%)$ & 79.76 & 79.91 & & \\
\hline Chi2 test & & & & 7.62 & 0.022 \\
\hline Impurity by stones & a high level & 0.60 & 0.00 & & \\
\hline & a low level & 23.41 & 4.86 & & \\
\hline & no impurity & 75.98 & 95.14 & & \\
\hline Chi2 test & & & & 72.87 & 0.000 \\
\hline Impurity by paddy husks & a high level & 0.91 & 0.22 & & \\
\hline & a low level & 40.00 & 6.84 & & \\
\hline & no impurity & 59.09 & 92.94 & & \\
\hline Chi2 test & & & & 155.67 & 0.000 \\
\hline Grain length & round & 7.55 & 0.22 & & \\
\hline & medium & 32.78 & 55.19 & & \\
\hline & long & 59.67 & 44.59 & & \\
\hline Chi2 test & & & & 401.03 & 0.000 \\
\hline Tomato & & & & & \\
\hline Level rottenness & a high level & 0.82 & 0.00 & & \\
\hline & a low level & 37.24 & 1.77 & & \\
\hline & no rotten spots & 61.93 & 98.23 & & \\
\hline Chi2 test & & & & 188.41 & 0.000 \\
\hline Spots & a high level & 1.03 & 0.22 & & \\
\hline & a low level & 42.51 & 6.74 & & \\
\hline & no black spots & 56.47 & 93.03 & & \\
\hline Chi2 test & & & & 161.33 & 0.000 \\
\hline Size & small & 27.93 & 1.55 & & \\
\hline & medium & 41.89 & 62.91 & & \\
\hline & large & 30.18 & 35.54 & & \\
\hline Chi2 test & & & & 129.36 & 0.000 \\
\hline
\end{tabular}

${ }^{*}$ Chi2 test that quality availability is significantly different between Madagascar and India 
Table 3: Stated relative values of food attributes (in \% of average price level)

\begin{tabular}{|c|c|c|c|c|c|c|c|}
\hline & \multirow[b]{2}{*}{ compared to (default) } & \multicolumn{2}{|c|}{ Madagascar } & \multicolumn{2}{|c|}{ India } & \multicolumn{2}{|c|}{ T-test } \\
\hline & & Mean & SE & Mean & SE & t-value & $\operatorname{Pr}(|\mathrm{T}|>|\mathrm{t}|)$ \\
\hline \multicolumn{8}{|l|}{ Rice } \\
\hline medium level of broken rice & high level broken rice $(>15 \%)$ & 3.5 & 0.3 & 17.7 & 1.1 & -14.03 & 0.000 \\
\hline low level of broken rice $(<5 \%)$ & high level broken rice $(>15 \%)$ & 8.0 & 0.7 & 45.1 & 2.8 & -14.98 & 0.000 \\
\hline low level impurities of stone & high level impurities of stone & 3.4 & 0.3 & 17.5 & 0.9 & -16.08 & 0.000 \\
\hline no impurities of stone & high level impurities of stone & 9.1 & 0.8 & 44.2 & 3.0 & -13.14 & 0.000 \\
\hline low level impurities paddy husk & high level impurities paddy husk & 2.6 & 0.2 & 17.0 & 12.2 & -16.89 & 0.000 \\
\hline no impurities paddy husk & high level impurities paddy husk & 8.9 & 0.4 & 39.1 & 2.7 & -14.67 & 0.000 \\
\hline long grain length & medium grain length & 2.0 & 0.1 & 40.1 & 3.4 & -13.49 & 0.000 \\
\hline \multicolumn{8}{|l|}{ Tomato } \\
\hline low level rotten & high level rotten & 26.2 & 1.1 & 19.2 & 1.1 & 4.44 & 0.000 \\
\hline not rotten & high level rotten & 48.7 & 1.8 & 49.6 & 1.0 & -0.44 & 0.662 \\
\hline low level of spots & high level of spots & 13.3 & 0.9 & 16.7 & 0.9 & -2.61 & 0.010 \\
\hline no spots & high level of spots & 27.4 & 1.8 & 41.3 & 1.4 & -5.95 & 0.000 \\
\hline medium size & small size & 10.9 & 0.8 & 22.6 & 0.9 & -9.59 & 0.000 \\
\hline large size & small size & 30.0 & 1.3 & 34.1 & 1.5 & -2.14 & 0.033 \\
\hline
\end{tabular}


Table 4: Hedonic price regressions (pooled regressions; dep. var. is $\log (\mathrm{US} \$$ price per $\mathrm{kg}$ ))

\begin{tabular}{|c|c|c|c|c|c|c|c|c|c|}
\hline & \multirow[b]{2}{*}{ compared to (default) } & \multicolumn{3}{|c|}{ Madagascar } & \multicolumn{3}{|c|}{ India } & \multicolumn{2}{|c|}{ F-test** } \\
\hline & & coeff. & t-value & abs. $v^{\circ}$ & coeff. & t-value & abs.v $v^{\circ}$ & $\mathrm{F}$ & Prob $>F$ \\
\hline \multicolumn{10}{|l|}{ Rice* } \\
\hline medium level of broken rice & high level broken rice & 0.031 & 4.09 & 1.426 & 0.205 & 1.71 & 12.710 & 2.11 & 0.147 \\
\hline low level of broken rice $(<5 \%)$ & high level broken rice & 0.038 & 5.12 & 1.748 & 0.265 & 2.04 & 16.430 & 3.05 & 0.081 \\
\hline low level impurities of stone & high level impurities of stone & 0.000 & -0.09 & 0.000 & -0.029 & -0.41 & -1.798 & 0.16 & 0.687 \\
\hline low level impurities paddy husk & high level impurities paddy hus & 0.008 & 3.36 & 0.368 & 0.038 & 0.52 & 2.356 & 0.17 & 0.681 \\
\hline long grain length & medium grain length & 0.001 & 0.52 & 0.046 & 0.037 & 1.71 & 2.294 & 2.73 & 0.099 \\
\hline R2: overall & 0.9 & & & & & & & & \\
\hline Number of observations & & & & & & & & & \\
\hline \multicolumn{10}{|l|}{ Tomato* } \\
\hline not rotten & low level rotten & -0.021 & -0.48 & -0.525 & -0.022 & -0.24 & -0.616 & 0.00 & 0.994 \\
\hline no spots & low level of spots & 0.043 & 0.84 & 1.075 & 0.098 & 4.15 & 2.744 & 0.98 & 0.323 \\
\hline medium size & small size & 0.125 & 5.21 & 3.125 & 0.205 & 3.57 & 5.740 & 1.66 & 0.198 \\
\hline large size & small size & 0.281 & 8.91 & 7.025 & 0.242 & 4.2 & 6.776 & 0.37 & 0.546 \\
\hline $\mathrm{R} 2$ : overall & 0.9 & & & & & & & & \\
\hline Number of observations & & & & & & & & & \\
\hline
\end{tabular}

* country-specific intercept, variety measures, location dummies, retail characteristics included but not reported

** Chow-test of difference of coefficients between regressions

- Absolute price difference in US $\notin / \mathrm{kg}$, evaluated at the means (resp. 0.46 US\$ and 0.62 US\$ for Madagascar and India rice, 0.25 US\$ and 0.28 US\$ for Madagascar and India tomato)

Note: For comparison with Table 3 results, coefficients should be multiplied by 100 to obtain the relative price premium as a $\%$ of the average sales price. 